\title{
Patient Involvement During a Pathway of Home-Based Reablement for Older Persons: A Longitudinal Single-Case Study
}

\author{
Kari Ingstad (D) \\ Aud Moe (D) \\ Hildfrid Vikkelsmo Brataas \\ Faculty of Nursing and Health Sciences, \\ Nord University, Campus Levanger, \\ Levanger, Norway
}

Background: In recent years, home-based reablement has become an increasingly popular way to provide rehabilitation services. This health care service aims to enable older persons to live longer at home while reducing the need for institutionalization. To ensure the provision of high-quality services, there is a continual need for research on issues of user involvement and co-creation during the pathway of the reablement process.

Purpose: This study focused on user involvement and participation with health care professionals during the reablement process.

Methods: This was a longitudinal, instrumental single-case study, in which one 85-year-old female patient was followed over the pathway of a six-week reablement process. Data were collected at three stages, including the goal-mapping phase, evaluation phase, and three weeks after completing reablement.

Results: Our analyses revealed two themes for the goal-mapping phase (dialogue led by the care provider and main goal), three themes for the implementation phase (the home as the preferred setting, little influence on organizational factors, and participation, influence, and motivation), and three themes for the evaluation phase (patient understanding as a precondition, motivated by weak paternalism, and self-determination requires clear communication).

Conclusion: The patient becomes involved through a partly co-creation process. During this time, they are involved, motivated, and influenced over the pathway of reablement. Health care providers must avoid implementing too much control during the pathway of home-based reablement, as patients have contextual knowledge that care providers do not possess.

Keywords: activities of daily living, ADL, co-creation, reablement services, patient empowerment, patient participation

\section{Introduction}

Health care service designers must continually innovate their methods and procedures in order to address the growing demand for services, particularly due to the increasing number of older people in Western societies. ${ }^{1}$ This study focused on user involvement and participation with health care professionals during reablement, which is a rather new rehabilitation service delivery model, though difficult to separate from standard rehabilitation. ${ }^{2}$ Over the last few years, reablement has become a more frequent method of providing health care services, which is offered in patients' homes. ${ }^{3}$ The purpose is in accordance with health policies aimed at increasing independence rates among older persons, thus enabling them to live
Correspondence: Kari Ingstad Faculty of Nursing and Health Sciences, Postbox 93, Levanger, 760I, Norway Tel +47913 37332

Email Kari.ingstad@nord.no 
longer at home. In this regard, reablement services reduce the need for institutionalized care and/or home care, while optimizing peoples' health and functioning. ${ }^{4}$ Since the mid-2000s, this new service delivery may also reduce total health service costs. ${ }^{5}$ Studies also have shown that reablement can be effective over time, as it is associated with decreased homecare service utilization. ${ }^{4-6}$ However, the existing evidence regarding the effects of home-based reablement is still inconclusive, ${ }^{7}$ and it can be difficult to compile research results as it is not a service with standardized schemes.

\section{Reablement: A Service in the User's Home}

Reablement is primarily aimed at restoring or increasing a patient's level of functioning. As such, the process is designed to enhance individual physical and/or other functioning, increase or maintain independence during meaningful activities of daily living (ADLs) while at home, and reduce the need for long-term services. ${ }^{6}$ While home-based reablement is not a standardized treatment, common processual features include time-limited, intensive, goal-oriented treatments designed to improve performance in everyday living while continuously creating health. ${ }^{8,9}$ While it is essential to involve patients in the goal-setting process, ${ }^{10-12}$ research has also shown that there may be some level of overemphasis on their desire to participate. $^{12}$

There are different models of reablement, also named home-based rehabilitation or restorative care. In Norway, reablement is described as a time-limited, interdisciplinary team-based model of rehabilitation performed by health care professionals in the patient's home. In the case under study, the reablement plan was established by a health care team and then delivered by some of the health personnel on the team. ${ }^{13}$ The client-centered instrument "Canadian Occupational Performance Measure" (COPM) was used to structure conversations during the goal-mapping phase and the evaluation phase. Specifically, the COPM is an evidence-based outcome measure designed to capture a client's self-perception of performance in everyday living over time. ${ }^{14}$

\section{User Involvement and Co-Creation in Reablement Services}

The core of the user involvement concept is that health services recipients should be allowed to participate in their own care. While user involvement in reablement services has previously been defined as a positive attitude and willingness to engage in reablement activities, such involvement may be expressed in different ways. ${ }^{11}$ User involvement is also related to empowerment, which refers to the restructuring of relations by providing agency to those with limited power. In the context of reablement, empowerment emphasizes the need to help patients acquire knowledge so they can take control of their own bodies, diseases, and treatments. ${ }^{15}$ Empowerment thus allows the user and health worker to engage in a process of cocreation.

Value co-creation can be defined as joint activities of both parties (patient and health care personnel) to contribute to the value that emerges for one or both parties. ${ }^{16}$

A prerequisite for co-creation is user involvement. User involvement can be understood as the relationship between the user and the professional. ${ }^{17}$ In this context, professionals provide services based on knowledge they have acquired through specialized education programs, including theoretical and practical applications. ${ }^{18,19}$ On the other hand, the user's personal experiences also constitute important knowledge; in fact, this is of equal importance as any professional knowledge, as treatment outcomes are often dependent on the inclusion of these perspectives. Such knowledge is typically relayed during direct conversations between the user and their health professional, thus increasing the awareness that both parties are mutually influential. ${ }^{20}$ Indeed, Trappes-Lomax and Hawton (2012) found that effective reablement was dependent on cooperation and motivation from the patient. ${ }^{21}$ The care team should therefore make demands while also providing support, thereby increasing the user's confidence in their own opportunities and resources. ${ }^{22}$ Given the establishment of both self-competence and trust in professional expertise, users are likely to invite professionals into the co-creation process. ${ }^{12}$

User participation in health care services is emphasized via general health policy guidelines and is also a recognized value within the health sector. ${ }^{17}$ Nevertheless, a number of studies have shown that patients are only given limited involvement in the design of their own health services. ${ }^{23-25}$ In the reablement process, user involvement has previously been explored during the startup phase, with a focus on goal formulation. However, relatively little scholarly attention has been placed on whether and how patients are involved throughout the reablement process. This highlights the need for additional knowledge concerning user involvement and co-creation, ranging from the beginning to the end of the reablement 
process. This knowledge is important for all engaged professionals, especially for ensuring the provision of highquality services.

\section{Aim}

This study investigated user involvement and participation with health care professionals during the reablement process with the goal of acquiring a better understanding of both elements in the context of home-based reablement.

The following RQ was highlighted: How does the patient's involvement and experiences of co-creation appear during the reablement process?

\section{Materials and Methods}

This was a longitudinal, instrumental single-case study in which one patient's involvement and experiences of cocreation were investigated over a six-week reablement pathway. The research question was thus targeted through a case that was bounded within a delimited system ${ }^{26}$ (ie, reablement in the context of one Norwegian municipal health care system). As an instrumental case study, this research clarified the above issues by exploring particular aspects of the investigated phenomenon. ${ }^{27,28}$ Through a longitudinal design and naturalistic methodology, we explored reablement involvement and co-creation with health care professionals on a reablement team during the reablement pathway as experienced by one patient. Naturalistic inquiry, which provides a methodological underpinning for this study, is grounded in the belief that knowledge can be developed inductively via methods that are emergent and flexible when new information emerges through obtained data. ${ }^{29,30}$

\section{Purposeful Sampling and Recruitment}

This study employed purposeful sampling, in which patient selection is based on judgments concerning which individual(s) are most representative and informative. ${ }^{31}$ The head administrator of a home-based reablement rehabilitation project assisted with the selection of a participant whom she considered to be typical for home-based reablement. We recruited one female reablement patient who was 85 years of age, lived in her own private home, and needed reablement in order to continue managing everyday activities. We consecutively included health professionals on the reablement team who conducted talks with the patient at the beginning and end of the reablement process. The team consisted of an occupational therapist, a physiotherapist, a nurse, and two care workers with training in reablement.

We provided written information to the patient and all reablement team members, each of whom voluntarily agreed to participate in this study. Following this, we distributed audio recorders to the participating health care personnel and instructed them on how to use the devices during goal setting and evaluation conversations.

\section{Data Collection}

The reablement process lasted six weeks. Data were collected at three stages, including the goal-mapping phase, evaluation phase, and three weeks after completing reablement (Figure 1).

Stage 1 included field observations, in which we obtained one audio recording of one naturally occurring conversation between the reablement patient and a care provider on the reablement team. As this meeting was conducted prior to the reablement program, the interlocutors discussed goal setting in the context of the reablement process. We transcribed the audio recording, which was 11,485 words in length.

Stage 2 also included field observations, in which we obtained a recording of one naturally occurring conversation between the patient and a care provider on the reablement team. This meeting was conducted during the sixth week of the reablement program, with the interlocutors therefore discussing their evaluation of the reablement process. The transcribed conversation was 5886 words in length.

Stage 3 included a qualitative in-depth interview with the reablement patient three weeks after the reablement program had ended. The second author conducted the interview, as they had extensive experience with qualitative interviewing and research in the field of reablement. The interview lasted one hour and seven minutes, with a transcribed conversation of 5882 words in length.

All data were collected in the patient's home. Following the conversations held in phases one and two,

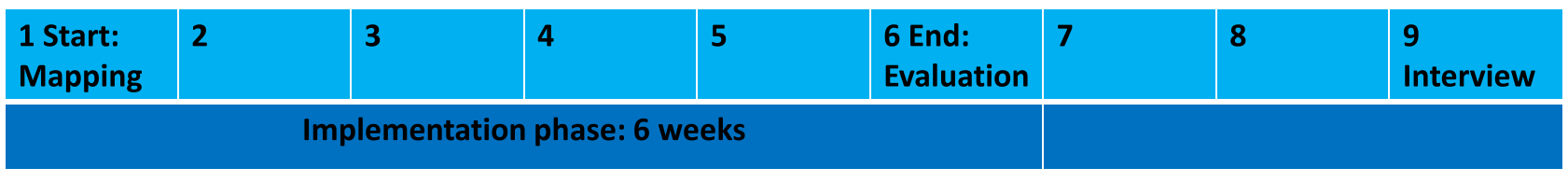

Figure I The study pathway and three data collection points. 
the team returned the sound recorder so that we could transcribe the text, which was done on a verbatim basis. We carefully noted which individuals were speaking in all cases.

\section{Analyses}

To understand the complexity of the study case, our analyses focused on describing and understanding the context, events, and themes. ${ }^{26}$ Following previous research, the embedded within-case analyses focused on patient involvement as the specific aspect of the case. ${ }^{26,32}$ We subjected three sets of data to content analyses, centered on the following steps: ${ }^{32}$

- Identifying the case history. All three datasets were read several times to obtain a robust impression of the patient's history and situation while gaining a better understanding of what led to the reablement service.

- Identifying the chronology of events during the reablement pathway stages. This included field observations 1 (being mapping) and 2 (end evaluation), which respectively provided data from the reablement initiation event and closing phase of the reablement process (Figure 1). The end evaluation component specifically provided data on the patient and care provider in the context of their evaluation of the implementation phase and how this met the patient's reablement goals. This interview was conducted three weeks after the completion of reablement and thus provided data on the patient's experiences of involvement and co-creation during the reablement process in its entirety (ie, initiation, implementation, and end evaluation).

- Thematic analysis. We determined how the data could clarify the study issue as it related to user involvement, including how this was experienced by the patient during different phases of the reablement pathway. Preliminary themes emerged during the analysis and coding of meaningful units in all three datasets. To develop and ensure appropriate themes, we tested and specified each preliminary theme. Through an iterative process involving continual revision of the tentative results, ${ }^{33}$ our reflections, writings, and re-coding of the material in its entirely generated a final set of themes. Table 1 shows an overview of the themes that emerged in each of the three reablement phases.
Table I An Overview of Themes Emerging in Each of the Three Reablement Phases

\begin{tabular}{|l|l|}
\hline $\begin{array}{l}\text { Phase of the Reablement } \\
\text { Process }\end{array}$ & Theme \\
\hline The goal-mapping phase & $\begin{array}{l}\text { Dialogue led by the care provider } \\
\text { Overall goal }\end{array}$ \\
\hline The implementation phase & $\begin{array}{l}\text { The home as the preferred setting } \\
\text { Little influence on organizational } \\
\text { factors } \\
\text { Participation, influence and } \\
\text { motivation }\end{array}$ \\
\hline The evaluation phase & $\begin{array}{l}\text { Patient understanding as } \\
\text { a precondition } \\
\text { Motivated by weak paternalism } \\
\text { Self-determination requires clear } \\
\text { communication }\end{array}$ \\
\hline
\end{tabular}

- Reflecting on the results of each reablement phase. In light of the research question, we considered the actions reported by the patient and health care personnel as they related to patient involvement. We further reflected on the patient's involvement within and between all three reablement phases.

- Interpretation. We elucidated the total meaning of the case to ensure a robust understanding of all pertinent issues (ie, user involvement throughout the homebased reablement process). This involved considerations of any new knowledge that was produced. This step is further detailed in the Discussion section.

\section{Results}

In this section, we first describe the case context and provide a chronology of events that occurred during the reablement intervention. Next, we outline the themes our analyses revealed for user involvement and participation during the pathway of the reablement process.

\section{Context}

This study followed Anna, who was 85 years of age at the time of reablement. She had four children, eight grandchildren, two great grandchildren, and lived in a one-story detached house about two hundred meters from her son. In fact, her entire family lived nearby and made regular visits. Anna had worked as a housewife since marriage but had been widowed for almost two years. She continued to cook for herself and ate dinner with her son 
each day. Regarding her medical history, Anna had undergone several major procedures, including a foot amputation that required a prosthesis (26 years prior to reablement), prosthetic installments in both hips, and a heart surgery (11 years prior to reablement). While at home, she used crutches or a wheelchair, but used a minicross bike while outdoors. In her earlier years, Anna was socially active and participated in groups such as the Norwegian Women's Sanitation Association. However, she had gradually become less active, which contributed to a weight gain of $20 \mathrm{~kg}$ over the preceding 30-year period.

Anna found it challenging to move around both indoors and outdoors. Over the last few years, some facility upgrades had thus been made in the home. Anna also used some functional/protective devices, including a toilet raiser, bath chair, hospital bed, and security alarm. Her relatives helped her shop for groceries and clean the house. In addition to reablement, home nurses helped her put on the prosthesis each morning and assisted with showering once a week, which they had done for several years.

Anna needed some additional help due to the general aging process, abovementioned weight gain, and increased immobility. In fact, it seemed imminent that she would be moved to a full-time nursing home. Moreover, this risk increased because she was beginning to have problems using the toilet by herself and was told that she must be able to do so if she wished to remain at her current residence. It was in this context that the home-based reablement process was initiated.

\section{Chronology of Events During the Reablement Intervention}

The reablement process lasted six weeks and consisted of the following three phases:

\section{The Goal-Mapping Phase}

On the first day, an occupational therapist from the reablement team visited Anna. At this time, her resources/challenges were mapped, thus providing a basis for clarifying the rehabilitation goals. The COPM was used to structure the conversation. The first meeting with Anna was used to decide which activities and measures would be implemented over the full six weeks.

\section{The Intervention Phase}

This consisted of the six-week reablement period, in which care providers from the reablement team visited Anna five times each week. The visits were mainly conducted by an occupational therapist and a care worker with training in reablement. However, a nurse and a physiotherapist also conducted some of the visits. They were all assisting Anna with her fixed activity plan. The team held regular meetings.

\section{The Evaluation Phase}

The reablement process was evaluated following its completion by the same occupational therapist who visited Anna on the first day. The COPM was used to detect changes in Anna's self-perception of occupational performance over time.

\section{User Participation During a Reablement Pathway}

The following sections discuss the themes pertaining to user involvement and participation during the reablement pathway based on our analyses:

\section{The Goal-Mapping Phase}

During this phase, our field observations revealed that dialogues revolved around the following topics: the patient's life and interests, health and functioning, problem identification, goal formulation, and practical planning for the reablement program. With regard to patient involvement and co-creation, the analysis revealed two themes: 1) dialogue led by the care provider, and 2) the main goal.

\section{Dialogue Led by the Care Provider}

The goal-mapping phase was implemented to map the patient's situation, discuss plans for reablement, and set specific goals for the reablement process. A challenge immediately arose during the first meeting, in which Anna and the care provider had different knowledge bases. While the care provider understood the nature of home-based reablement, Anna did not. However, she obtained a general idea of the concept via the discussion. During the interview after completing the reablement pathway, Anna said:

I didn't understand much of it when I started.

The reablement pathway began quickly, with many decisions being made during the first meeting. At this time Anna needed to acquire a substantial amount of information over a short time period. To map her challenges, the care provider began by asking an open-ended question to 
determine what was most challenging. This dialogue revealed that major challenges were related to her foot:

Care provider: It sounds a bit like you need to strengthen your foot so that you can still move about on your own.

Anna: If my foot were ok, everything would be fine.

Care provider: Shall we make it a goal to strengthen your foot, then?

Anna: Yes, but I do not understand what I need to do.

Care provider: There's a physiotherapist and an occupational therapist on the team.

Anna: Yes, if that foot would only get better, I think things would be fine.

Care provider: Then I will write down one goal here: that is, to strengthen your foot so you can still move around and go to the toilet on your own.

The goal-mapping phase was based on what Anna found challenging in her everyday life. At this time, the dialogue was led by the care provider, but both Anna and the care provider co-created her reablement goals. Since care providers and patients have different knowledge bases, they tend to discuss these issues from different starting points. In this case, the care provider attempted to describe specific reablement goals while Anna talked about her challenges, which included her foot, her prosthesis, activities, and especially the difficulty she experienced when using the toilet.

\section{The Main Goal}

Following completion of the reablement pathway, the researcher asked about the goal of reablement:

Anna: They agreed that I should keep the physical part that I could do myself. They want us to stay at home as long as possible.

Researcher: Was that the goal, then?

Anna: I think so ... they said I can stay at home as long as it's possible.

There is one main pathway goal behind all discussions involving reablement measures and other related goals: patients should stay at home as long as possible.

\section{The Implementation Phase}

We derived data related to the implementation phase based on interviews the researcher held with Anna. Three themes emerged: 1) the home as the preferred setting, 2) little influence on organizational factors, and 3) participation, influence, and motivation.

\section{The Home as the Preferred Setting}

Home-based reablement entails care providers visiting patients in their homes. Several times Anna said she thought it was highly advantageous to hold the reablement process in her own home, as this avoids the burden of traveling to see a physiotherapist or other health care providers:

Anna: It's a nice arrangement that they come to your home, because travelling can be difficult ... I am very grateful to be at home, because it's a lot of bother to go to a physiotherapist, for example.

\section{Little Influence on Organizational Factors}

Anna had little influence on organizational factors, such as when the visits would occur and who would arrive. Although the agreement was for care providers to arrive at $9 \mathrm{am}$, she often had to wait longer:

Anna: I get up by myself and wash and get dressed. Then I sit and wait for the home nurses to come. They come at nine, but sometimes it's half past eleven. It's actually most suitable for me if they arrive at 10 o'clock, because then I have got ready properly.

Not only did Anna have little influence on the time when she would receive reablement, she also had little say in how long reablement would last. In this municipality, home-based reablement lasts six weeks, regardless of the patient's challenges or whether the goals have been achieved. Further, patients have no influence over which members of the reablement team arrive each day or how many different people will visit them during the program:

Researcher: Did you feel there were a lot of different people who came to your house?

Anna: Not at all. There are lots of them, but I know them all. It's quite ok with me.

\section{Participation, Influence, and Motivation}

Through discussions, the care providers and Anna created a plan for the reablement pathway, specifically based on the challenges Anna experienced. This plan contained goals for the pathway and described the activities Anna would perform. She described this as follows:

Anna: It was just like a school timetable And it said what I had to do. I did it twice a day. It was not very easy, but I managed it.

Researcher: Do you feel that you were able to take part and decide things in the program by yourself, to tell them what you wanted? 
Anna: Yes. Well, ye-es. I did the exercises they told me to do.

Researcher: But do you think they listened to what you wanted?

Anna: Yes, they did. I got into a kind of routine, so that I do it myself. I think that must be the point of it.

The implementation phase included both participation, influence, and motivation. In the beginning, the health care professionals influenced her in terms of activity and exercise, and Anna agreed with them. This motivated Anna to complete the reablement program. While once very sedentary, she become much more active after the pathway. In an interview with the researcher following completion, Anna said:

They [the home-based reablement team] motivated me. Last year, I sat without a prosthesis more than I've ever done for 30 years, because the prosthesis didn't fit. It was difficult to wear it. I sat still too much, I had no energy to ... They've encouraged me to do these exercises.

Reflecting upon the reablement, Anna said:

It was an awakening. It pushed me to do the exercises every morning and evening.

\section{The Evaluation Phase}

During this phase, dialogues dealt with several topics, including the patient's expectations, experiences, goal achievements, and program satisfaction. Regarding patient involvement and co-creation, our analysis revealed three themes: 1) patient understanding as a precondition, 2) motivated by weak paternalism, and 3) self-determination requires clear communication.

\section{Patient Understanding as a Precondition}

During the final phase, the patient and care provider evaluated the reablement program as a totality. The COPM was also used to guide this process. Using a scale ranging from 1-10, Anna assessed how well she had mastered various activities:

Care provider: How well do you think you did today? Number 1 means you did not succeed at all, and number 10 means you did extremely well.

Anna: Well, it will not be either 1 or 10 , it must be something in between. If there's someone there with me I can reach 7, but I am a bit more skeptical when I am by myself, but I have done it.
Care provider: But it's not only about getting up out of a chair, it's also about when you get out of bed and out of your wheelchair and ...

Anna: Oh I see, then I think we can put it in the middle, about ... 6 or 7 , then, somewhere in the middle.

It is challenging for an individual to categorize their own performance on a scale from 1-10. Patients are unfamiliar with the form the first time they use it, but the process becomes easier the second time. It is also vital to understand the context (ie, what the question is really about). In the above example, Anna initially thought the question pertained solely to her ability to get up from a chair, but later she understood that it referred to getting up in general. In order for patients to become involved in the evaluation of their own reablement process in a way that they clearly understand, they must be provided with the explicit context of the process. They must also have a precise understanding of the questions.

\section{Motivated by Weak Paternalism}

Anna's motivation to exercise increased during the reablement pathway. While initially a bit skeptical of the plan, she became more motivated to engage in the activities and exercises over time:

Care provider: At first, when we came you were a bit skeptical about whether this was the right thing for you, whether there was any point in exercising.

Anna: Yes, I'd given up, or accepted the fact that I'd had a good life.

Care provider: But you have been very motivated to exercise, have not you?

Anna: Yes, I have been, and I still am.

Through discussions and motivation, the reablement pathway made Anna more willing to exercise. Behind this motivation lay the basic understanding that she would be required to move to a care home if she could no longer look after herself. Anna said:

Now, I realize that I'll have to apply for a place in the care home if I can't go to the toilet by myself.

\section{Self-Determination Requires Clear Communication}

During the evaluation phase, Anna and the care provider discussed how to adapt her home to make it easier for her to continue living there. For example, removal of doorsteps was considered to prevent falls. Such adaptations 
entailed changes in the house design that may have required assistance from her son:

Care provider: Is it okay if we contact your son and talk about, for example, doorsteps and things like that? Because that will make it easier for you to move about.

Anna: I do not think we need to start sawing off any doorsteps. I can easily get across.

Care provider: But is it okay if we call your son and talk about it, anyway? In any case, you are the ones who will ultimately decide on this.

Anna: I do not think we should talk to him about those doorsteps.

Care provider: Have I understood you right that you do not want us to ring your son?

Anna: No, you do not have to do that yet.

As indicated here, the patient's wishes may differ from recommendations provided by healthcare professionals. Nevertheless, they can still arrive at solutions through the cocreation process. In the above example, the care provider asked about the same issue three times, which can be interpreted as an attempt to persuade Anna. In this situation, Anna made no concessions, and ultimately, she made the final decision. However, patients may not always express their wishes as clearly, which may require care providers to "read between the lines" in order to determine their actual desires. To be heard and have their wishes fulfilled, patients must therefore be able to communicate clearly.

\section{Discussion}

In Scandinavia, user participation is a generally emphasized aspect of national health policies and is a recognized value in the context of health care services. ${ }^{17}$ A collective voice has been supplemented with more individualized involvement mechanisms based on both choice and direct userinvolvement in individual decision-making and the planning of individually tailored health care services. ${ }^{34,35}$ This study has explored how the patient's involvement and experiences of cocreation during the reablement process appear. The study shows that the reablement pathway emerged as a partial cocreation process in which the patients were involved, motivated, and influenced. While the initial goal-mapping phase also entailed co-creation between the patient and care provider, this was subject to weak paternalism; that is, the healthcare professionals had the expertise and knowledge of reablement needed for achieving success. On the other hand, the implemented goals and actions were based on the patient's perceptions of the challenges they would confront as well as their desire to improve. Studies show that involving patients in goal setting is essential; ${ }^{10-12}$ however, patients' lack of knowledge about both the process and pathway make it crucial to provide them with helpful information. The extent to which the patient is actually involved is thus related to the care provider's communication skills. ${ }^{36,37}$ When interpreted as user-set goals, this means that user involvement may be overemphasized during the goal-mapping phase. ${ }^{12}$ The power inherent from the care provider's position may also influence patients to behave submissively, which results in an unequal power relationship during co-creation rather than establishing empowerment and self-agency. However, patient participation is encouraged through dialogues in which care providers ask open-ended questions to clarify issues, which requires active listening skills. ${ }^{38}$

During the implementation phase, patients are involved in decisions related to certain aspects of the reablement program, but not as a whole. In this regard, they have limited opportunities to influence organizational factors. For example, the reablement program lasts six weeks regardless of the patient's situation. They also have little say in who will visit them or at what times. While Anna did not mind receiving visits from many different care providers, there was considerable variation in the arrival times, meaning she often had to wait. Health care in Norway is operated and financed by the public sector. Home nursing is a free health service, with the aim of providing universal access and equitable distribution. However, seniors in Norway have fewer choices between different service providers than in other Nordic countries. ${ }^{39}$ Patient involvement in Norwegian senior care may be more inclined toward influence and discussions than the unconditional right to decide between care services and providers. ${ }^{23,40}$

In this study, Anna said the reablement program initially seemed rather extensive, but she did what she was told to do and completed the program. After a while she became more motivated to do the exercises by herself. In regard to decision-making, a paternalistic approach can be justified by the need to balance the patient's wishes with professional knowledge and ethics. Patients may also have limited beliefs in their own abilities and resources upon starting a reablement program, but these elements can be strengthened when teams provide support and give clear information about the plan while also presenting certain requirements. A dynamic interaction based on a balance between requirements and support seems to help patients enter a positive stage in which they experience mastery, thus enhancing the reablement process. $^{22}$ In this way, weak paternalism may be necessary for encouraging 
patients to exercise and remain active, which they may find highly beneficial, especially after the program.

Clinical experience and evidential research must be juxtaposed with the patient's preferences. During the evaluation phase, Anna clearly stated that she did not want to involve her son and did not wish to make certain alterations to her home, such as removing doorsteps. However, health care professionals should use the power of their knowledge to persuade patients about important issues, such as fall prevention. One might expect that home-based reablement may lead to an increased risk of falling. ${ }^{41}$ In this case, however, Anna still made the final decision. To ensure patient autonomy, care providers must not only use their professional knowledge, but also listen to the patient's wishes while striving to understand the entire context of their situation. While patients are usually influenced by this knowledge, the particular level of influence varies based on individual and contextual factors. ${ }^{42,43}$ As mentioned, patients also have contextual knowledge that care providers do not possess. For example, Anna considered other factors to be of greater importance than fall prevention. In some cases, it may be questioned whether health care professionals sufficiently emphasize the patient's entire context, as well as what this means to the patient. Professionals must thus avoid implementing too much control or adopting overly paternalistic behaviors, instead aiming for patient involvement that includes real participation in decision-making. They should strive to see the whole picture, as patients may have different motives, and may variously relate to participation in co-creation processes.

In sum, this study found that co-creation occurred partly through a specific home-based reablement pathway. However, general guidelines should still be applied to all co-decisions made in this process, thus properly influencing the choices made by both the patient and care provider. Most notably, the patient should stay at home as long as possible while striving for continued independence. In this way, user participation at the individual level can work as a tool for achieving the care policy objective stating that older persons should live in their own homes as long as it is feasible for them to do so. ${ }^{23,44}$ In these circumstances, user participation entails that patients are responsible for their own lives and health while preventing passivation and dependence on public assistance. ${ }^{23}$

\section{Strengths and Limitations}

This study had many strengths, but also some limitations. Regarding the limitations, our results were based on a single case and cannot necessarily be generalized to other samples and situations. However, our aim was not to generalize but to describe a specific example of patient involvement in homebased reablement. In our study, we emphasized contextual descriptions and obtaining a large number of quotations. This increases credibility while allowing the reader to assess how far the results can be transferred to similar situations. We consider it a strength that the patient was followed throughout the pathway, as this shows how their involvement evolved. Further, three experienced researchers closely collaborated throughout the research process, were all involved in the analyses and discussions, and agreed on the themes that emerged. It should also be noted that this study was solely conducted in Norway, meaning that both the care providers and patients viewed home-based reablement from the Norwegian perspective.

\section{Conclusion}

This single case study adds valuable information to the literature concerning how patient participation manifests during the reablement process. During the goal-mapping phase, the patient knew little about the reablement process and was dependent on the care provider's communication skills in order to gain involvement. During the implementation phase, the patient became more familiar with the reablement process and increased their participation in decision-making. However, the health professionals still influenced the patient in terms of activity and exercise. Finally, the evaluation phase revealed that weak paternalism can motivate patients during reablement and may be necessary to encourage continued exercise and activity, which is eventually considered very beneficial. As patients are also influenced by the care provider's knowledge, health care professionals must avoid implementing too much control, as patients will have contextual knowledge that their care providers do not possess.

We also found some structural barriers in the co-creation process. For example, patients have limited control over organizational factors (eg, how long the rehabilitation process takes as well as who will visit and at what times). Further, the care providers must use the available resources and may therefore not always be able to fulfill the patient's wishes. Finally, this case study should inform future research, as continued investigation is needed to determine how organizational factors promote and inhibit patient involvement during home-based reablement.

\section{Abbreviations}

ADL, activities of daily living; NSD, Norwegian Social Science Data services; COPM, Canadian Occupational Performance Measure. 


\section{Ethical Approval}

The patient has been given a fictive name. Both the patient and reablement team members provided written informed consent to participate in this study and have quotes published. The patient confirmed to have her case details published in this study. This study was approved by the Norwegian Social Science Data services (NSD), project number 34297. The researchers provided all participating patients and health care professionals with oral and written explanations of the research. All participation was voluntary. To ensure confidentiality, we have not provided any of the raw data. The manuscript complies with the principles stated in the Declaration of Helsinki.

\section{Acknowledgments}

The authors thank all study participants, including the patients and reablement team.

\section{Author Contributions}

All authors contributed to data analysis, drafting or revising the article, gave final approval of the version to be published, agreed to the submitted journal, and agree to be accountable for all aspects of the work.

\section{Disclosure}

The authors report no conflicts of interest in this work.

\section{References}

1. Eurostat 2019. Ageing Europe. Looking at the lives of older people in the EU. Available from: https:/ec.europa.eu/eurostat/documents/ 3217494/10166544/KS-02-19\%E2\%80\%91681-EN-N.pdf/c701972f6b4e-b432-57d2-91898ca94893. Accessed May 18, 2021.

2. Clotworthy A, Kusumastuti S, Westendorp RGJ. Reablement through time and space: a scoping review of how the concept of 'reablement' for older people has been defined and operationalized. BMC Geriatr. 2021;21:61. doi:10.1186/s12877-020-01958-1

3. Cochrane A, McGilloway S, Furlong M, Molloy DW, Stevenson M, Donnelly M. Home-care "re-ablement" services for maintaining and improving older adults' functional independence. Cochrane Database Syst Rev. 2013;11:CD010825. doi:10.1002/14651858.CD010825

4. Tessier A, Beaulieu MD, Mcginn CA, Latulippe R. Effectiveness of reablement: a systematic review. Healthc Policy. 2016;11(4):49-59.

5. Zingmark M, Norström F, Lindholm L, Dahlin-Ivanoff S, Gustafsson S. Modelling long-term cost-effectiveness of health promotion for community-dwelling older people. Eur J Ageing. 2019;16 (4):395-404. doi:10.1007/s10433-019-00505-1

6. Metzelthin SF, Rostgaard T, Parsons M, Burton E. Development of an internationally accepted definition of reablement: a Delphi study. Ageing Soc. 2020;1-16. doi:10.1017/S0144686X20000999

7. Bersvendsen T, Jungeilges J, Abildsned E. Empirical evaluation of home-based reablement: a review. Nord $J$ Health Econ. 2021;1-18. doi: $10.5617 /$ njhe. 7838
8. Aspinal F, Glasby J, Rostgaard T, Tuntland H, Westendorp RG. Reablement: supporting older people towards independence. Age Ageing. 2016;45(5):574-578. doi:10.1093/ageing/afw094

9. Tuntland H, Espehaug B, Forland O, Hole AD, Kjerstad E, Kjeken I. Reablement in community-dwelling adults: study protocol for a randomised controlled trial. BMC Geriatr. 2014;14(1):1-9. doi:10.1186/1471-2318-14-139

10. Baker DI, Gottschalk M, Eng C, Weber S, Tinetti ME. The design and implementation of a restorative care model for home care. Gerontologist. 2001;41(2):257-263. doi:10.1093/geront/41.2.257

11. Jokstad K, Skovdal K, Landmark BT, Haulelien H. Ideal and reality: community healthcare professionals' experiences of userinvolvement in reablement. Health Soc Care Community. 2019;27:907-916. doi:10.1111/hsc. 12708

12. Jokstad K, Hauge S, Landmark BT, Skovdal K. Control as a core component of user involvement in reablement: a qualitative study. J Multidiscip Healthc. 2020;13:1079-1088. doi:10.2147/JMDH.S269200

13. Moe A, Brataas HV. Interdisciplinary collaboration experiences in creating an everyday rehabilitation model: a pilot study. $J$ Multidiscip Healthc. 2016;18(9):173-182. doi:10.2147/JMDH.S103696

14. Law M, Baptiste S, McColl MA, Opzoomer A, Polatajko H, Pollock N. The Canadian occupational performance measure: an outcome measure for occupational therapy. CJOT. 1990;57 (2):82-87. doi:10.1177/000841749005700207

15. Aujoulat I, Marcolongo R, Bonadiman L, Deccache A. Reconsidering patient empowerment in chronic illness: a critique of models of self-efficacy and bodily control. Soc Sci Med. 2008;66 (5):1228-1239. doi:10.1016/j.socscimed.2007.11.034

16. Zhang L, Tong H, Demirel O, Duffy V, Yih Y, Bidassie B. A practical model of value co-creation in healthcare service. Procedia Manuf. 2015;3:200-207. doi:10.1016/j.promfg.2015.07.129

17. Askheim OP, Christensen K, Fluge S, Guldvik I. User participation in the Norwegian welfare context: an analysis of policy discourses. J Soc Policy. 2016;46(3):583-601. doi:10.1017/S0047279416000817

18. Zimmerman Nilsson M. Practical and theoretical knowledge in contrast: teacher educators' discursive positions. Aust J Teach Educ. 2017;42(8):29-42.

19. Brante T. Professional fields and truth regimes: in search of alternative approaches. Comp Sociol. 2010;9(6):843-886. doi:10.1163/ $156913310 \mathrm{X} 522615$

20. Vatne S. Brukermedvirkning og involverende pedagogikk. [User participation and involving pedagogy]. In: Brataas, Evensen \& Ingstad, editor. Pedagogisk Praksis I Sykepleie. [Nursing Pedagogy]. Oslo: Gyldendal Akademisk; 2019:75-93.

21. Trappes-Lomax T, Hawton A. The user voice: older people's experiences of reablement and rehabilitation. J Integr Care. 2012;20 (3):181-195. doi: $10.1108 / 14769011211237528$

22. Jokstad K, Landmark BT, Hauge S, Skovdal KI. Eldres erfaring med hverdagsrehabilitering. mestring og muligheter - krav og støtte i dynamisk samspill. [Adults' experiences with reablement]. Tidsskr Omsorgsforsk. 2016;2(3):212-221. doi:10.18261/issn.2387-5984-201603-07

23. Johannessen AM, Steihaug S. Brukermedvirkning i helsetjenester for eldre - en kvalitativ studie av to kommunale akutte døgnenheter og samarbeidende kommuner. [User participation in healthcare for elderly - a qualitative study]. Tidsskr Omsorgsforsk. 2019;5 (2):1-14. doi:10.18261/issn.2387-5984-2019-02-04

24. Kvæl LAH, Debesay J, Bye A, Bergland A. Health-care professionals' experiences of patient participation among older patients in intermediate care - at the intersection between profession, market and bureaucracy. Health Expect. 2019;22(5):921-930. doi:10.1111/hex.12896

25. Dyrstad DN, Testad I, Storm M. Older patients' participation in hospital admissions through the emergency department: an interview study of healthcare professionals. BMC Health Serv Res. 2015;15 (1):1-9. doi:10.1186/s12913-015-1136-1 
26. Creswell JW. Qualitative Inquiry \& Research Design. Choosing Among Five Approaches. Newbury Park, CA: Sage Publications; 2007.

27. Stake RE. The Art of Case Study Research. Thousand Oaks, CA: Sage Publications; 1995.

28. Anthony S, Jack S. Qualitative case study methodology in nursing research: an integrative review. J Adv Nurs. 2009;65(6):1171-1181. doi:10.1111/j.1365-2648.2009.04998.x

29. Sjöblom LM, Hellzèn O, Lilja L. "I screamed for help": a single case study of one sister's experiences with formal psychiatric care when her brother became mentally ill. Health. 2013;5(3):417-425. doi:10.4236/health.2013.53056

30. Lincoln Y, Guba EG. Naturalistic Inquiry. Newbury Park, CA: Sage Publications; 1985

31. Polit DF, Beck CT. Nursing Research: Generating and Assessing Evidence for Nursing Practice. 10th ed. Philadelphia, PA: Wolters Kluwer; 2017.

32. Yin RK. Case Study Research: Design and Method. 3rd ed. Thousand Oaks, CA: Sage Publications; 2003.

33. Morgan DL, Nica A. Iterative thematic inquiry: a new method for analyzing qualitative data. Int J Qual Methods. 2020;19:1-11. doi:10.1177/1609406920955118

34. Vrangbaek K. Patient involvement in Danish health care. J Health Organ Manag. 2015;29(5):611-624. doi:10.1108/JHOM-01-20150002

35. Ringard A, Sagan A, Saunes IS, Lindahl AK. Health systems in transition. Health. 2013;15(8):1-162.
36. Askheim OP. Empowerment as guidance for professional social work: an act of balancing on a slack rope. Eur J Soc Work. 2010;6 (3):229-240. doi:10.1080/1369145032000164546

37. Brataas HV, Thorsnes S, Hargie O. Themes and goals in cancer outpatient-cancer nurse consultations. Eur J Cancer Care. 2010;19 (2):184-191. doi:10.1111/j.1365-2354.2008.01040.x

38. Moe A, Ingstad K, Brataas HV. Patient influence in home-based reablement for older persons: qualitative research. BMC Health Serv Res. 2017;17:736. doi:10.1186/s12913-017-2715-0

39. Szebehely M, Meagher G. Nordic eldercare - weak universalism becoming weaker? J Eur Soc Policy. 2018;28(3):294-308. doi:10.1177/0958928717735062

40. Sørvoll J, Gautun H. User participation in Norwegian elder care - do local governments follow the lead of care 2020? Tidsskr Omsorgsforsk. 2020;1(6):1-16. doi:10.18261/issn.2387-5984-202001-09

41. Bersvendsen T. Effects of Home-Based Reablement: A MicroEconometric Approach [Dissertation]. Kristiansand, Norway: University of Agder; 2020.

42. Brataas HV, Evensen AE. Modell for pasientundervisning. In: Brataas, evensen \& ingstad, editor. Pedagogisk Praksis I Sykepleie. [Nursing Pedagogy]. Oslo: Gyldendal Akademisk; 2019:75-93.

43. Stein-Parbury J. Patient \& Person. 4th ed. Chatswood, NSW: Elsevier Australia; 2009.

44. Martens CT. Aging in which place? Connecting aging in place with individual responsibility, housing markets, and the welfare state. J Hous Elder. 2018;32(1):1-11. doi:10.1080/02763893.2017.1393483
Journal of Multidisciplinary Healthcare

\section{Publish your work in this journal}

The Journal of Multidisciplinary Healthcare is an international, peerreviewed open-access journal that aims to represent and publish research in healthcare areas delivered by practitioners of different disciplines. This includes studies and reviews conducted by multidisciplinary teams as well as research which evaluates the results or conduct of such teams or healthcare processes in general. The journal

\section{Dovepress}

covers a very wide range of areas and welcomes submissions from practitioners at all levels, from all over the world. The manuscript management system is completely online and includes a very quick and fair peer-review system. Visit http://www.dovepress.com/testimonials. php to read real quotes from published authors. 